\title{
Effect of Tantalum Additions to a Cobalt-Chromium-Nickel Base Alloy
}

\author{
A. P. ROWE, W. C. BIGELOW, and K. ASGAR \\ University of Michigan, School of Dentistry, Ann Arbor, Michigan 48104, USA
}

An investigation by electron diffraction, transmission and scanning electron microscopy, and energy-dispersive X-ray analysis has shown that $T a$ additions to a 40-30-30 Co-Cr-Ni-base alloy strengthen by ordering and by formation of coherent $\alpha-\mathrm{Co}_{3} \mathrm{Ta}$ precipitate. However, increasing $T a$ content increases the proportion of the hexagonal phase and decreases ductility.

The effect of additions of tantalum (Ta) to a 40-30-30 cobalt (Co)-chromium (Cr) nickel (Ni) alloy has been studied for several years at the University of Michigan. Mechanical properties of a series of these alloys have been reported by Mohammed and Asgar. ${ }^{1}$ Those results showed that an alloy containing $13 \% \mathrm{Ta}$ would have an ultimate tensile strength of $124,000 \mathrm{psi}$, a yield strength of $90,000 \mathrm{psi}$, and an elongation of $10 \%$. There is a sharp change in these properties around 12 to $13 \% \mathrm{Ta}$.

In the present study, this system was examined by electron diffraction, transmission and scanning electron microscopy, and energy-dispersive $\mathrm{X}$-ray analysis to identify the microstructure associated with these mechanical properties.

\section{Materials and Methods}

Specimens were prepared by conventional investment casting techniques with the use of a wax pattern, phosphate-type investment, and centrifugal casting from a zircon crucible under argon. The structures of the as-cast specimens are extremely sensitive to the cast-

This investigation was supported by USPHS Research Grant DE-02017 from the National Institute of Dental Research, National Institutes of Health, Bethesda, Md, and is based on a dissertation submitted in partial fulfillment of the $\mathrm{PhD}$ requirements, University of Michigan, 1973.

Received for publication August 24, 1973. ing cross-section, which of course influences the cooling rate. Therefore, one series of specimens was cast in the form of $2.5-\mathrm{mm}$ plates; another was cast in $0.6-\mathrm{mm}$ plates. The plates were then ground down mechanically to about $0.15 \mathrm{~mm}$ and electropolished in perchloric acid-ethanol to thicknesses suitable for electron microscopy.

\section{Results and Discussion}

Alloy compositions containing up to $16.7 \%$ Ta consist primarily of a face-centered cubic matrix phase and an interdentritic hexagonal phase. Sometimes minor amounts of $\sigma$ phase are present. Depending on the $\mathrm{Ta}$ content and the casting conditions, there also may be fine precipitates of $\alpha-\mathrm{Co}_{3} \mathrm{Ta}, \beta-\mathrm{Co}_{3} \mathrm{Ta}$, and $\gamma-\mathrm{Co}_{2} \mathrm{Ta}$.

Figure 1 shows the distribution of the $\beta$ (hexagonal) phase in these samples as revealed by scanning electron microscopy. The light areas have been identified from electron diffraction patterns as the $\beta$ phase, which evidently dissolves more slowly in the etching solution than does the surrounding $\alpha$ phase.

The numbers on the micrographs indicate the nominal, as weighed, $T$ a contents in weight percentages. The actual compositions are somewhat different.

The table lists the results of energy-dispersive X-ray analysis of these alloys. For each specimen type the first row lists the weight percentages of each component as weighed for the casting; the second row indicates the actual compositions as determined by analysis. The castings contained an average of $19 \%$ more $\mathrm{Ta}, 8 \%$ more $\mathrm{Cr}, 9 \%$ less $\mathrm{Co}$, and $6 \%$ less $\mathrm{Ni}$ than weighing indicated. The remaining two rows for each casting represent average compositions of the facecentered cubic $(\alpha)$ and hexagonal $(\beta)$ phases. 

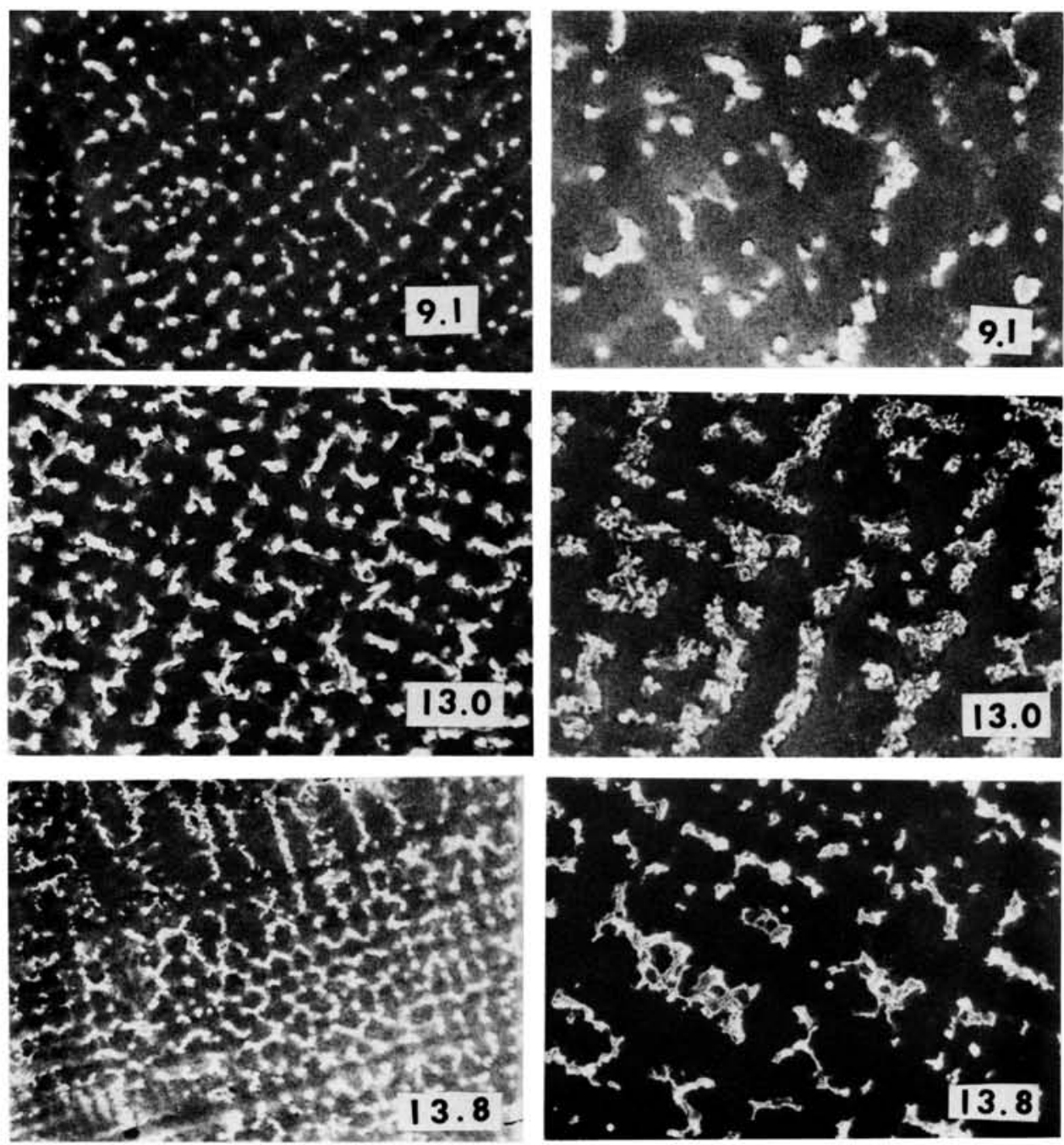

FIG 1.-Scanning electron micrographs show distribution of $\beta$ phase in $\mathrm{Co}-\mathrm{Cr}-\mathrm{Ni}-\mathrm{Ta}$ alloys. Top, 0.6-mm castings; right, 2.5-mm castings.

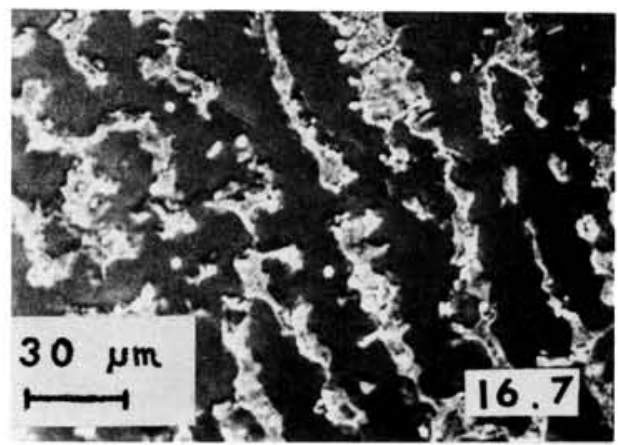


TABLE

Energy Dispersive X-Ray ANALyses of Co-Cr-Ni-Ta Alloys

\begin{tabular}{|c|c|c|c|c|c|c|}
\hline Casting & $\begin{array}{c}\text { Phase } \\
\text { Fraction of } \beta\end{array}$ & & $\mathrm{Ni}$ & Co & $\mathrm{Cr}$ & $\mathrm{Ta}$ \\
\hline \multicolumn{7}{|c|}{ Thin castings $(0.6 \mathrm{~mm})$} \\
\hline \multirow{4}{*}{$9.1 \% \mathrm{Ta}$} & & Weighed & 27.3 & 36.3 & 27.3 & 9.1 \\
\hline & 0.19 & Analyzed & 26.3 & 34.0 & 30.1 & 9.6 \\
\hline & & $\alpha$ & 26.5 & 34.5 & 36.0 & 3.0 \\
\hline & & $\beta$ & 15.2 & 21.0 & 17.6 & 46.2 \\
\hline \multirow{4}{*}{$13.0 \% \mathrm{Ta}$} & & Weighed & 26.1 & 34.8 & 26.1 & 13.0 \\
\hline & 0.35 & Analyzed & 24.2 & 32.3 & 27.7 & 15.8 \\
\hline & & $\alpha$ & 25.8 & 35.2 & 35.6 & 3.4 \\
\hline & & $\beta$ & 16.1 & 21.7 & 17.8 & 44.4 \\
\hline \multirow{4}{*}{$13.8 \% \mathrm{Ta}$} & & Weighed & 25.9 & 34.5 & 25.9 & 13.8 \\
\hline & 0.41 & Analyzed & 24.5 & 31.3 & 28.2 & 16.0 \\
\hline & & $\alpha$ & 25.9 & 34.2 & 34.6 & 5.3 \\
\hline & & $\beta$ & 18.7 & 23.5 & 18.8 & 39.0 \\
\hline \multicolumn{7}{|c|}{ Thick castings $(2.5 \mathrm{~mm})$} \\
\hline \multirow{4}{*}{$9.1 \% \mathrm{Ta}$} & & Weighed & 27.3 & 36.3 & 27.3 & 9.1 \\
\hline & 0.16 & Analyzed & 25.8 & 33.2 & 30.0 & 11.0 \\
\hline & & $\alpha$ & 26.4 & 35.0 & 31.0 & 7.6 \\
\hline & & $\beta$ & 17.2 & 21.9 & 20.2 & 40.7 \\
\hline \multirow{4}{*}{$13.0 \% \mathrm{Ta}$} & & Weighed & 26.1 & 34.8 & 26.1 & 13.0 \\
\hline & 0.33 & Analyzed & 24.4 & 31.6 & 28.2 & 15.8 \\
\hline & & $\alpha$ & 25.9 & 33.7 & 30.2 & 10.2 \\
\hline & & $\beta$ & 16.9 & 23.9 & 18.8 & 40.4 \\
\hline \multirow{4}{*}{$13.8 \% \mathrm{Ta}$} & & Weighed & 25.9 & 34.5 & 25.9 & 13.8 \\
\hline & 0.37 & Analyzed & 24.6 & 31.3 & 28.2 & 15.9 \\
\hline & & $\alpha$ & 24.8 & 33.1 & 30.3 & 11.8 \\
\hline & & $\beta$ & 15.1 & 22.5 & 16.4 & 46.0 \\
\hline \multirow{4}{*}{$16.7 \% \mathrm{Ta}$} & & Weighed & 25.0 & 33.3 & 25.0 & 16.7 \\
\hline & 0.47 & Analyzed & 21.9 & 29.0 & 26.6 & 22.5 \\
\hline & & $\alpha$ & 24.2 & 32.9 & 29.7 & 13.2 \\
\hline & & $\beta$ & 13.2 & 19.1 & 17.0 & 50.7 \\
\hline
\end{tabular}

Note: All values reported as weight percentages.

Analyses of $\sigma$ phase are not available for each of the castings, but a typical analysis is $23 \%$ $\mathrm{Ni}, 27 \% \mathrm{Co}, 24 \% \mathrm{Cr}$, and $25 \%$ Ta.

As the casting cooled, the $\alpha$ phase was the first to solidify. Its Ta content ranged from 3 to $13 \%$ for the various compositions, but was always less than the overall Ta content. As the temperature decreased, the remaining, Ta-rich ( 40 to $45 \%$ ) material solidified in a hexagonal structure, despite the fact that $\mathrm{Ta}$ additions are reported to favor the face-centered cubic structure. ${ }^{2}$ The Co-Ta binary phase diagram, ${ }^{3}$ for example, shows no hexagonal phase for a $\mathrm{Ta}$ content greater than $7 \%$.

Factors afFecting DUCTILITY.-The system studied here showed an increasing amount of hexagonal phase with increasing Ta content, and it is in this phase that failure is initiated. Figure 2 is a scanning electron micrograph of a longitudinal section of a tensile bar pulled to failure and shows cracks in the $\beta$ phase. Figure 3 is another such specimen in which there is evidence of pulling apart at the $\alpha-\beta$ interface. Fracture surfaces of the high-Ta, low-ductility specimens suggest that failure has occurred by interface shearing; the dendritic structure was left (Fig 4).

The thinner castings showed slightly more $\beta$ phase than did the thicker ones, and the $\alpha$ phase contained less $\mathbf{T a}$. In short, there was less time for $\alpha$ formation and Ta segregation to occur before the solidus was reached.

Also, in the thinner specimens, the distribution of $\alpha$ and $\beta$ phases was on a much finer scale than that in the thicker castings of the composition (Fig 1).

STRENGTHENING MECHANISMS.-At $9.1 \%$ Ta (charge composition), both the $\alpha$ and $\beta$ phases were solid solutions (Fig 5 ). At $13 \%$, 


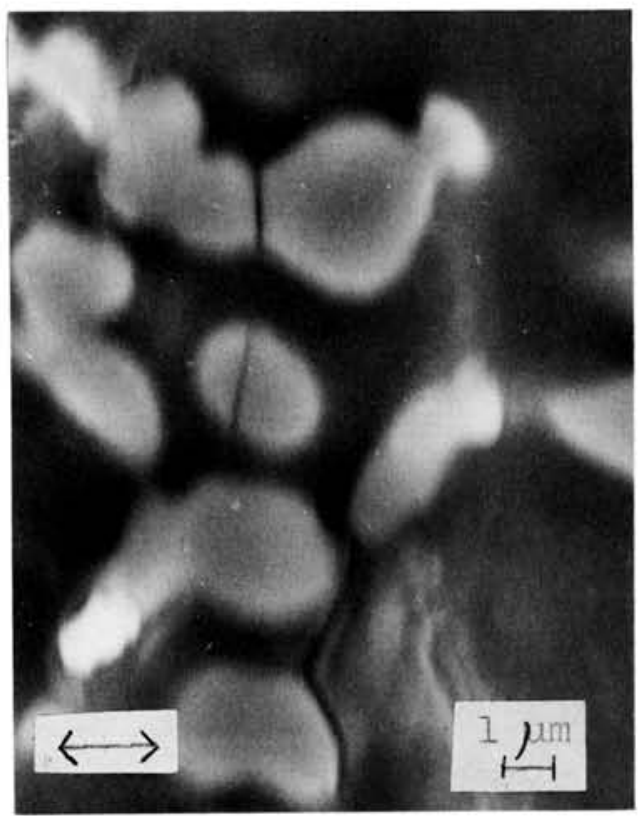

Fic 2.-Scanning electron micrograph of longitudinal section of tensile bar pulled to failure. Arrow, tensile direction.

the $\alpha$ phase, which is the predominant phase, was well ordered but there was no evidence of precipitate. Ordering is a well-recognized strengthening mechanism; it increases the Burger's vector of dislocations and impedes dislocation motion, particularly if antiphase boundaries are present.

At $13.8 \%$ Ta, a fine $(<50 \mathrm{~A})$ coherent precipitate was found in the thicker castings (Fig 6). It is described as $\alpha-\mathrm{Co}_{3} \mathrm{Ta}$, although its unit cell dimensions correspond to facecentered cubic Co rather than the slightly larger cell of $\alpha-\mathrm{Co}_{3} \mathrm{Ta}$. With higher concentrations of $\mathrm{Ta}$, the larger cell is found, the precipitate particles are larger, and at $16.7 \%$ some are no longer coherent. In fact, at this latter composition there also is precipitate in the hexagonal phase; it is $\gamma-\mathrm{Co}_{2} \mathrm{Ta}$, which has a hexagonal structure.

In the thinner, $0.6-\mathrm{mm}$ specimens, precipitate was not observed until $\mathrm{Ta}$ concentrations increased to more than $13.8 \%$ (Fig 7).

HEAT-TREATED SPECIMENS.-Of course none of these structures represents the equilibrium condition for this system. When the alloys

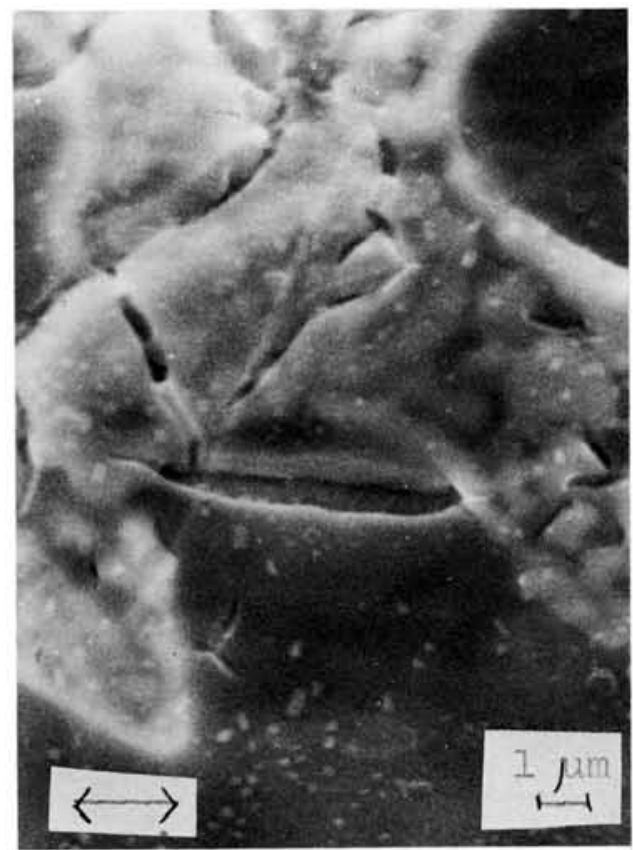

FIG 3.-Scanning electron micrograph of longitudinal section of tensile bar pulled to failure. Arrow, tensile direction.

were heat-treated at $700 \mathrm{C}$ for 20 hours, equilibrium was approached (but not reached). Heat-treated specimens with $\mathrm{Ta}$ as low as

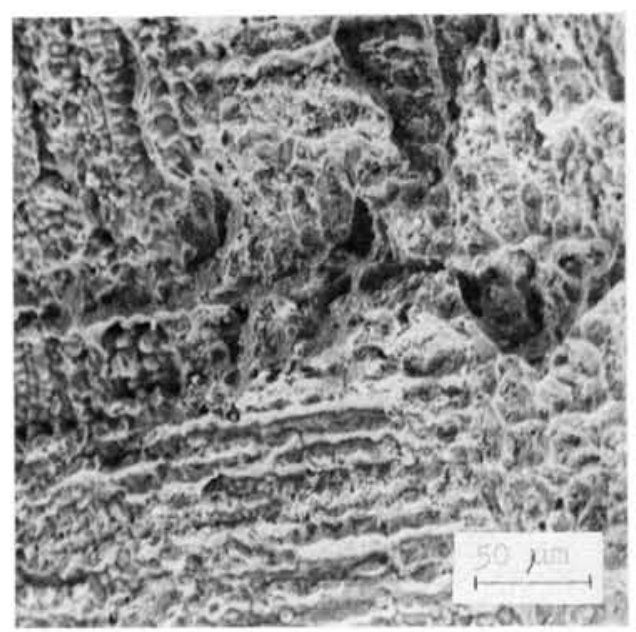

Fic 4.-Scanning electron micrograph of transverse section of $9.1 \% \mathrm{Ta}$ tensile bar pulled to failure. 


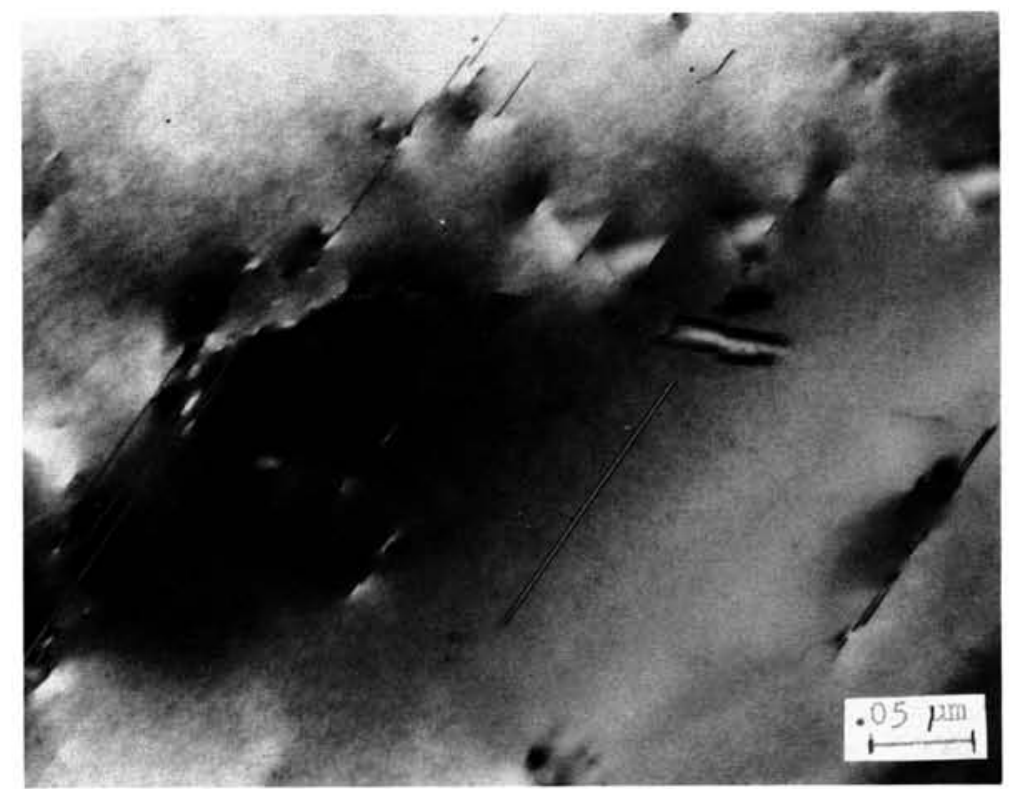

Fic 5.-Transmission electron micrograph of (110) $\alpha$ phase in $9.1 \% \mathrm{Ta}$ alloy.

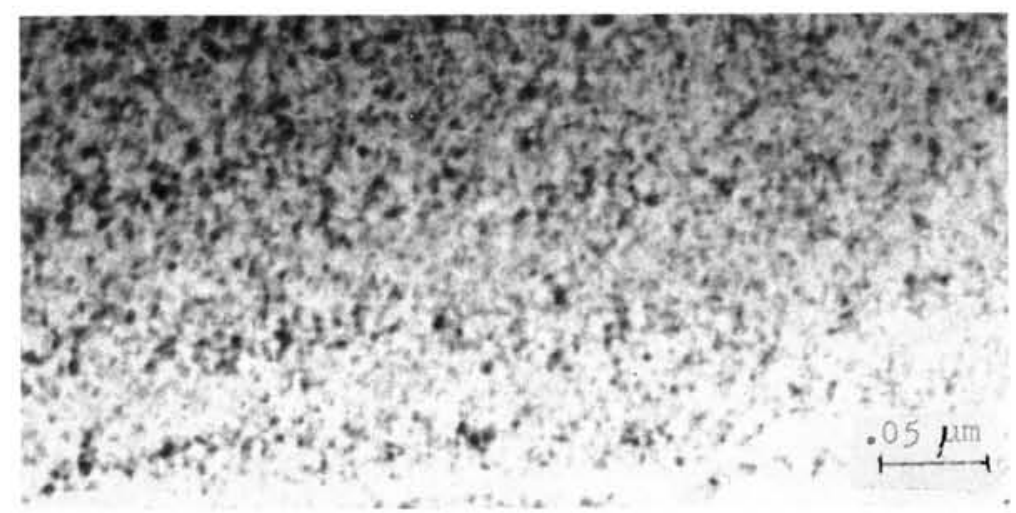

Fic 6.-Transmission electron micrograph of (110) ordered $\alpha$ phase in $13.8 \%$ Ta alloy. 


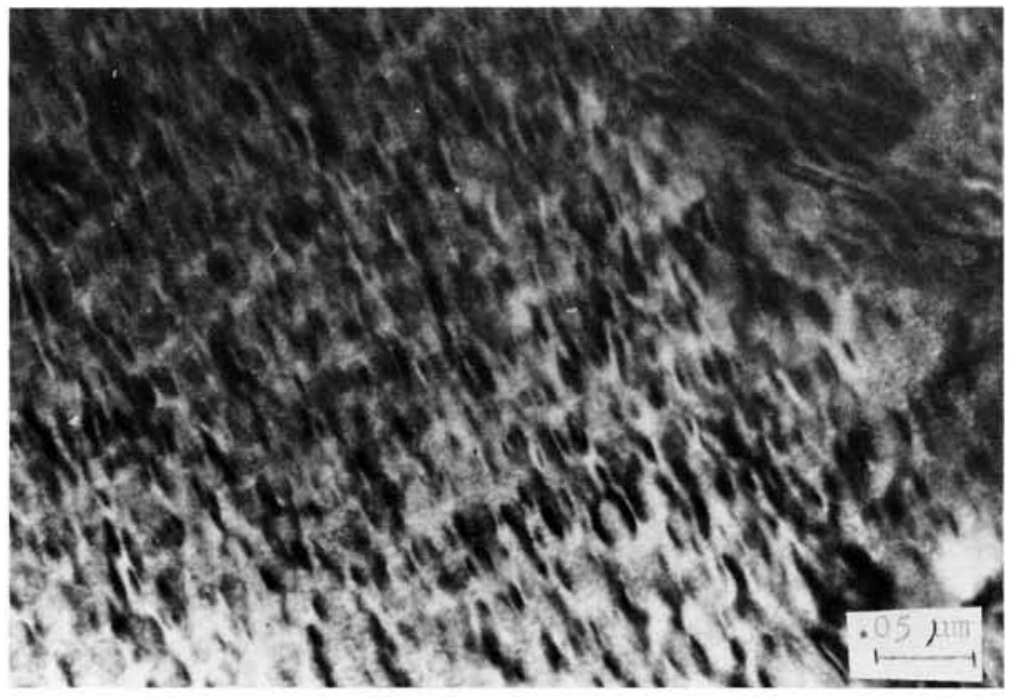

Fic 7.-Transmission electron micrograph of (100) ordered $\alpha$ phase and $\alpha-\mathrm{Co}_{3} \mathrm{Ta}$ in $13.8 \% \mathrm{Ta}$ alloy.

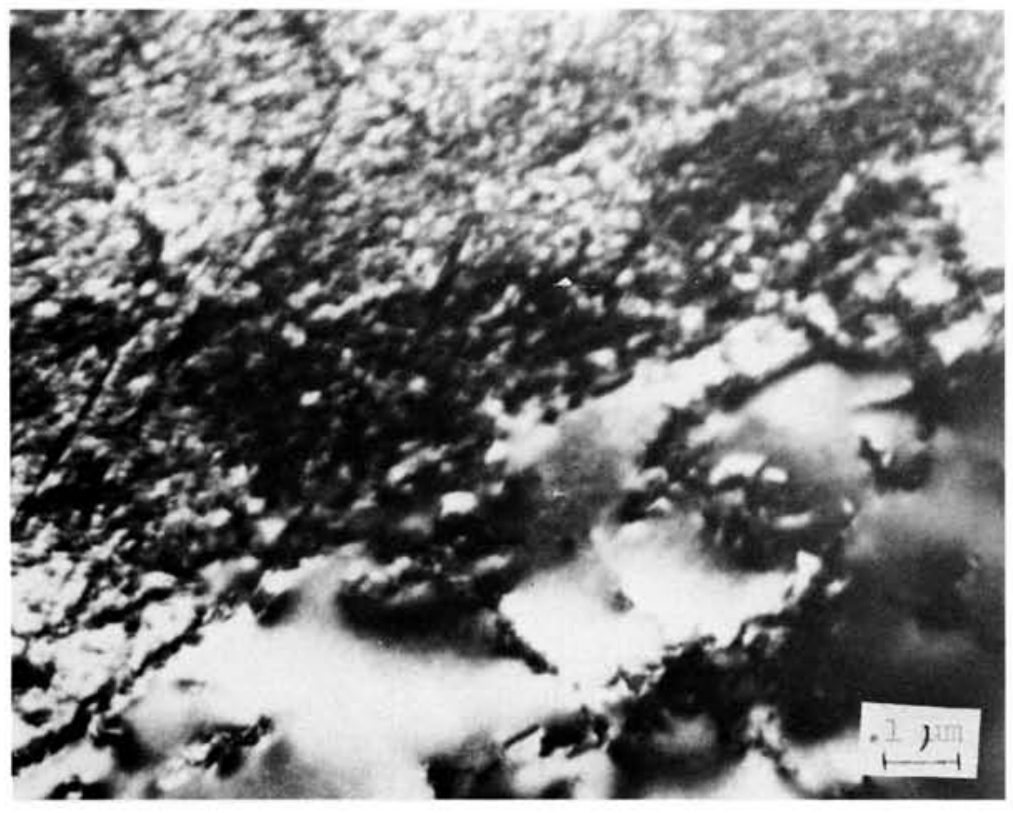

Fic 8.-Transmission electron micrograph of (110) $\alpha$ phase and $\alpha-\mathrm{Co}_{3} \mathrm{Ta}$ in heat-treated $9.1 \% \mathrm{Ta}$ alloy. 
9\% contained fine $\alpha-\mathrm{Co}_{3} \mathrm{Ta}$ precipitate in some regions of the $\alpha$ phase (Figs 8-10).

Higher $\mathrm{Ta}$ compositions contained larger precipitates (Fig 11) and also precipitates $\left(\beta-\mathrm{Co}_{3} \mathrm{Ta}\right.$ and $\left.\gamma-\mathrm{Co}_{2} \mathrm{Ta}\right)$ in the hexagonal phase. In the Co-Ta system, $\alpha-\mathrm{Co}_{3} \mathrm{Ta}$ is described as a metastable phase and $\beta-\mathrm{Co}_{3} \mathrm{Ta}$ is the equilibrium phase at $700 \mathrm{C}$.

Sigma PHASE.-This study has not included quantitative information on how much $\sigma$ phase occurs in each composition, but it has suggested that the embrittling influence of the $\sigma$ phase may have been overestimated, at least for this system.

For example, Figure 12 shows a specimen with a considerable quantity of $\sigma$ phase (the needles) surrounding each island of hexagonal phase. Yet this is a section of a tensile

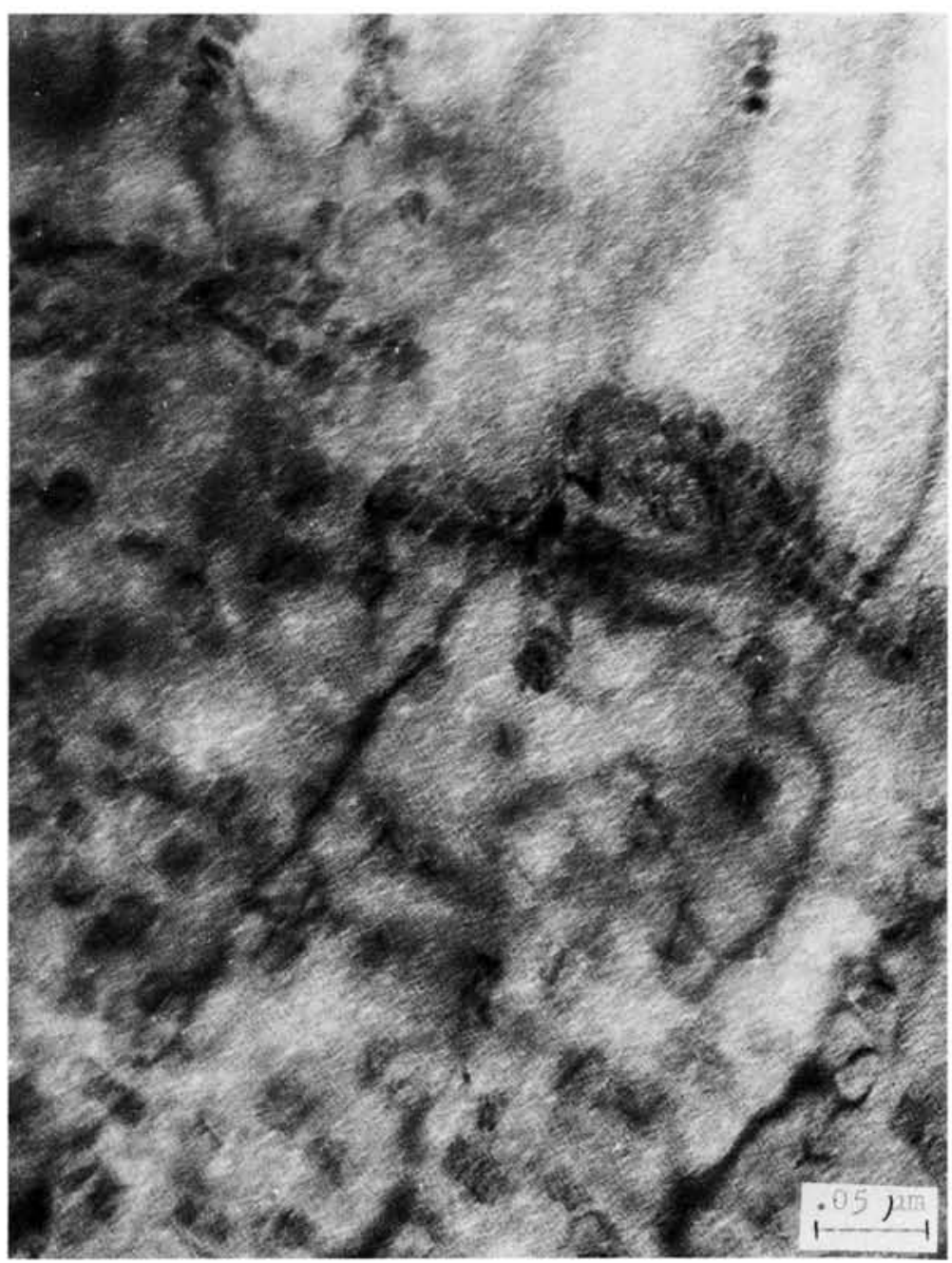

FIG 9.-Transmission electron micrograph of (130) $\alpha$ phase and $\alpha-\mathrm{Co}_{3} \mathrm{Ta}$ in heat-treated $9.1 \% \mathrm{Ta}$ alloy. 


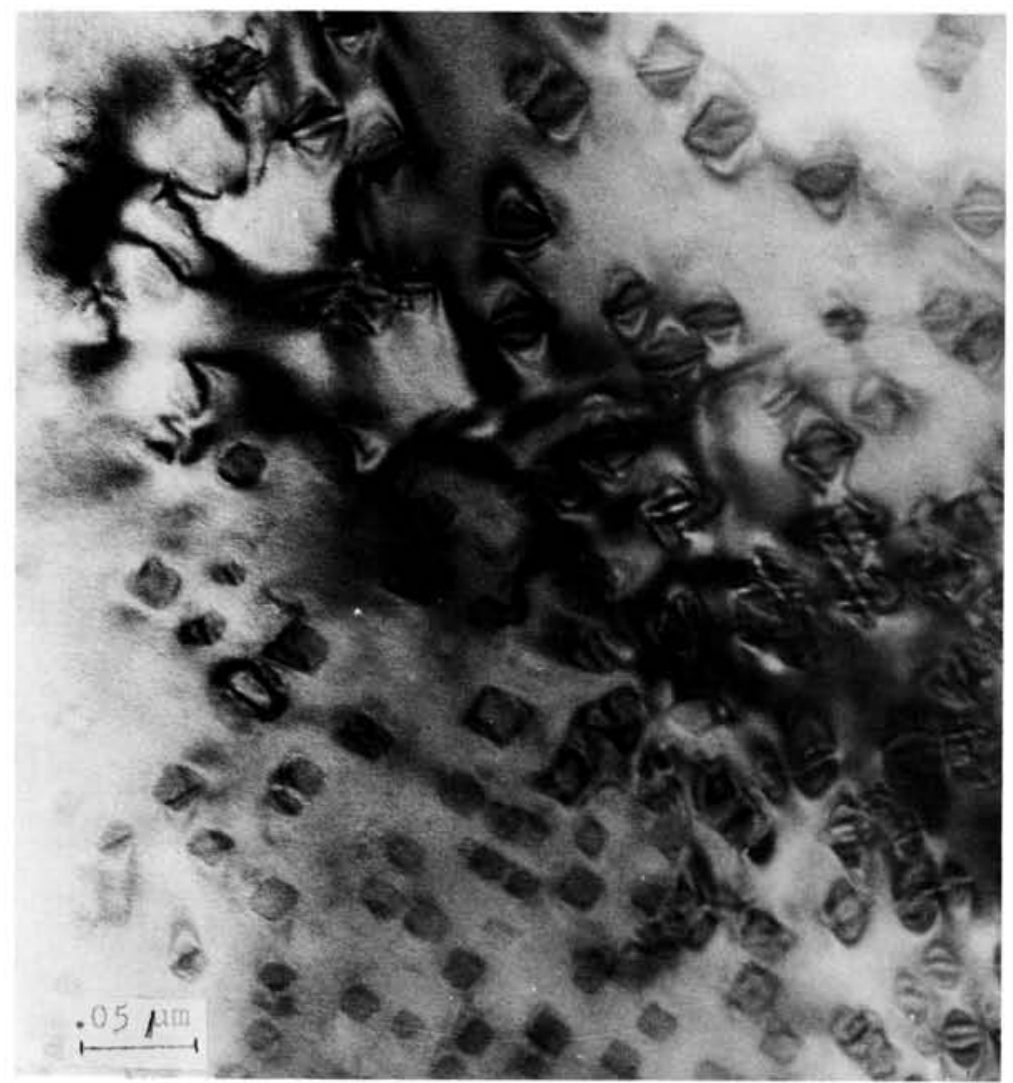

FIG 10.-Transmission electron micrograph of (100) $\alpha$ phase and $\alpha-\mathrm{Co}_{3} \mathrm{Ta}$ in heat-treated $9.1 \% \mathrm{Ta}$ alloy.

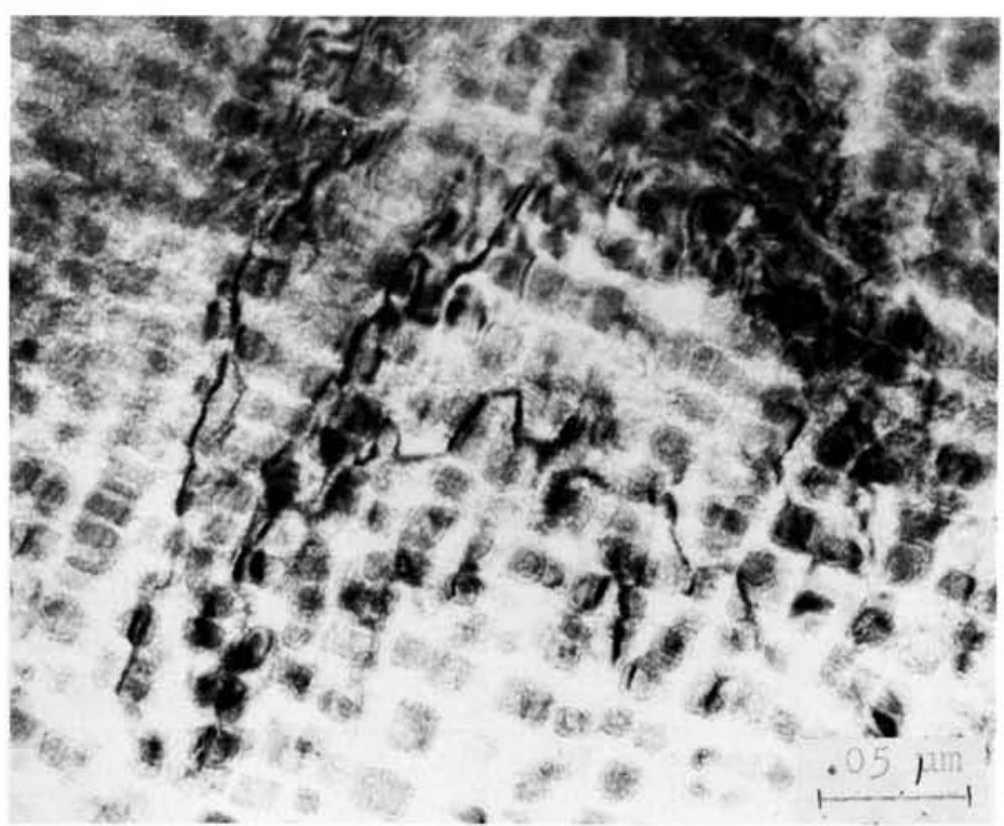

Fig 11.-Transmission electron micrograph of (120) $\alpha$ phase and $\alpha-\mathrm{Co}_{3} \mathrm{Ta}$ in heat-treated $16.7 \% \mathrm{Ta}$ alloy. 


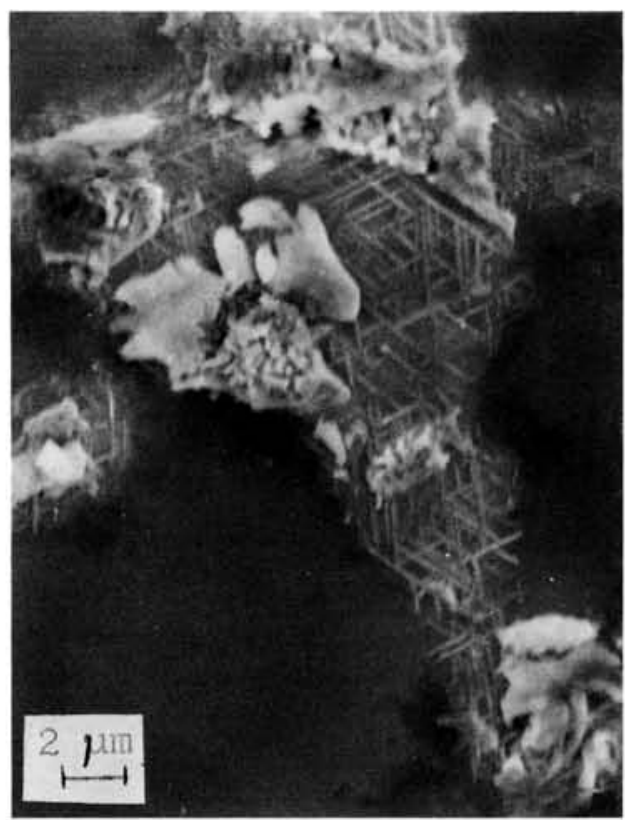

FIG 12.-Scanning electron micrograph of $9.1 \%$ Ta alloy shows $\alpha, \beta$, and $\sigma$ phases.

bar with an elongation of $14.5 \%$; and failure has started in the $\beta$ phase, not in the $\sigma$ phase.

\section{Conclusions}

As the $\mathrm{Ta}$ concentration is increased in this alloy system, strengthening is increased first by ordering of the $\mathrm{Ta}$ in the facecentered cubic phase and later by formation of a fine, coherent precipitate, $\alpha-\mathrm{Co}_{3} \mathrm{Ta}$. However, increasing the $\mathrm{Ta}$ concentration also increases the amount of the more brittle hexagonal phase and ductility decreases.

A desirable combination of these properties for dental applications was reported ${ }^{1}$ for $13 \% \mathrm{Ta}$, where strengthening is by ordering and elongation is about $10 \%$ for the 2.5-mm castings. In practical situations, where the thickness of partial denture clasps, for example, may vary between 1 and $2 \mathrm{~mm}$, Ta concentrations slightly less than $13 \%$ will be needed to achieve the desired properties. The thicker portion of such a casting would have a slightly different microstructure, with less hexagonal phase and more $\mathrm{Ta}$ in each phase; hence, it would have greater strength and greater ductility than the clasp region. The composition should be selected for optimum properties in the clasp. A slower cooling rate should improve the properties of these alloys.

Appreciation is due to D. K. MacCallum of the University of Michigan, School of Dentistry, for some of the transmission micrographs.

\section{References}

1. Mohammed, H., and Asgar, K.: A New Dental Superalloy System: II. Mechanical Properties, J Dent Res 52: 145-150, 1973.

2. Koster, W.: Uber den Einfluss der Elemente auf die polymorphe Umwandlung des Kobalts, Z Metallkunde 43: 297-303, 1952.

3. Korchynsky, M., and Fountain, R.W.: Precipitation Phenomena in Cobalt-Tantalum Alloys, Trans AIME 215: 1033-1043, 1959. 